POSSIBLE INFECTION OF MAN BY INDIRECT TRANSMISSION OF TRICHOPHYTON DISCOIDES

\author{
- \\ JACQUELINE WALKER, Ph.D. \\ Mycological Reference Laboratory, Public Health \\ Laboratory Service, London School of Hygiene \\ and Tropical Medicine
}

A notable increase in the number of cases of infection in man by Trichophyton discoides, the principal cause of cattle ringworm, diagnosed in various parts of Great Britain and Northern Ireland has been evident in recent years. This may be attributable in part to a higher proportion of the infected persons seeking medical assistance, but in greater measure to an actual increase in the incidence of the disease.

In many instances the infection in man can be traced to contact with an animal, usually a calf, suffering from ringworm, occasionally to contact with another human being; but in a significantly large number of cases there is no history of any direct contact with the disease. In such cases it has been assumed that the infection was transmitted in an indirect way by contact with infective hairs, scales, or crusts deposited, from animals, on the ground, on the woodwork of cattle stalls, on scratchingposts, and elsewhere. However, in support of this hypothesis little if any material evidence has been adduced.

The purpose of the present work was to seek for the infective morbid material in situations such as those mentioned above and also to consider the possibility of a natural saprophytic vegetation of the fungus from which infection might be contracted. In view of the recent reports on a natural habitat of Microsporum gypseum in the soil (Gordon et al., 1952 ; Gordon, 1953) this possibility seemed to be particularly relevant.

Materials and Methods.-Materials for examination were obtained from three farms in Northern Ireland, one in Hertfordshire, and one in Cornwall, on all of which active cattle ringworm existed. These materials consisted of scrapings from the walls of seven cowsheds, from five cattle stalls, nine field scratching-posts, samples of soil from the base of these nine posts, one fence rail, bark from two trees rubbed by cattle, and eight samples of cow dung. All specimens were examined in microscopic mounts for the presence of infected hair or scales, and selected portions were then plated out for culture on cycloheximide - tellurite - pen:cillin - streptomycin - maltextract agar.

\section{Results of the Examination}

Excluding the samples of cow dung, which yielded entirely negative results, hairs or epithelial scales were found in all but two of the specimens, and characteristically infected hairs were seen in two specimens-one from a scratchingpost and the other from the soil at the base of that post. $T$. discoides was isolated in culture from these two specimens and also from a scraping of the wall of a cowshed.

During the course of this study an instance came to notice indicating the long survival of the fungus in an inactive state under natural conditions. A herd of Jersey cows, apparently free from infection, was introduced into a new pasture that had not been grazed for two years; there were scratching-posts in the field. Two weeks later several of the animals developed ringworm and $T$. discoides was isolated from them. But there was nothing to show whether the infecting fungus had survived in the dormant parasitic form in shed hairs or scales or in a saprophytic vegetation.
In view of this observation, tests for survival time were made on 50 samples of $T$. discoides in infected hairs. These samples, protected in folded papers, were stored at laboratory temperature and examined at intervals for viability. All of the 50 were found viable at the end of 6 months, 49 at the end of 9 months, 38 at the end of 12 months, and 29 at the end of 15 months. It seems probable, therefore, that under natural conditions some of the dormant parasitic spores, protected in cracks or fissures in bark or woodwork, would have an equally long survival period.

The possibility that the fungus may be able to survive in nature in a saprophytic form -was also investigated. No such form had been seen in any of the specimens examined microscopically, and, moreover, in artificial culture on the common nutrient media, $T$. discoides, which is usually deficient in the power to synthesize essential vitamin B, forms only a glabrous, dysgonic growth with no characteristic spore forms. However, when preformed vitamin B; as thiamine, is added to the medium, a richer growth, sometimes containing microconidia and macroconidia, may develop (Mackinnon and Artagaveytia-Allende, 1948 ; Georg, 1950 ; Blank, 1953).

Tests were made of the capacity of the fungus to vegetate on soil and other natural substrata. The materials used were: (1) the top soil from a chicken run, $p \mathrm{H} 6$; (2) soil from a fresh mole-hill on an alluvial deposit, $p \mathrm{H} 8.5$; (3) alluvial deposit from a river bank, $p \mathrm{H} 8.5$; (4) light top soil over chalk, $p \mathrm{H} 8.5$; (5) light top soil over gravel, $p \mathrm{H} 7$; (6) marl over chalk, $p \mathrm{H} 5.5$; (7) cultivated garden soil, $p \mathrm{H} 7$; and (8) cow dung, $p \mathrm{H} 8$. The materials were spread in Petri dishes and sterilized in the autoclave at $15 \mathrm{lb}$. per sq. in. ( $1 \mathrm{~kg}$. per sq. $\mathrm{cm}$.) for 30 minutes.

On each sample of soil and on the dung sowings were made of the parasitic stage of the fungus in fragments of hair from three cases of human and one case of bovine infection, and parallel sowings were made from pure cultures of $T$. discoides previously isolated from the four morbid specimens. These 64 samples were incubated at $26^{\circ}$ C. for four weeks, the humidity of the soil being maintained by regular additions of sterilized distilled water. After one week an initial growth, represented by a few short mycelial filaments, was demonstrable from all the sowings, but no further development occurred except on the mole-hill and chicken-run soils and the cow dung. On the chicken-run soil the ultimate growth from all sowings was poor and glabrous, and microscopically showed no conidial form but only a few chlamydospores. On the cow dung a heaped, waxy, brownish growth developed from all sowings, and two weeks later small white powdery areas appeared on the glabrous surface of the colonies. Microscopical examination of aerial mycelium from these areas showed abundant production of microconidia; in the glabrous part of the colony chlamydospores were found, but no conidia. On the mole-hill soil the three strains from infected human hair yielded growths resembling those formed on the hen-run soil and did not form conidia, but the strain from the cow developed a colony with a white duvet, which on microscopical examination showed numerous microconidia and some macroconidia.

\section{Discussion}

The observations detailed above show that infective material containing the parasitic spores of $T$. discoides, from ringworm on cattle, may be deposited on scratchingposts or other woodwork against which the animals may rub, and on the ground beneath. As the parasitic spores may remain viable in storage under laboratory conditions at room temperature for 15 months and longer, it may be assumed that similar spores deposited on posts or woodwork and protected in cracks or fissures from sunlight and other inimical agencies would have a correspondingly long survival period. From such situations man and susceptible animals may be infected.

The capacity of the fungus to vegetate on certain types of soil and on cow dung, and to develop a conidial form, affords another possible mechanism of the infection, in which the infecting form is the conidium of the saprophytic 
growth developing on soil or another suitable substratum from deposited parasitic spores. Soils contaminated with bird and animal droppings have been found to provide a natural habitat of Histoplasma capsulatum (Emmons, 1949 ; Ajello and Zeidberg, 1951), and it seems possible that in the present study the better results obtained in culture on cow dung, mole-hill soil, and chicken-run soil may have been due to the presence of animal excreta.

\section{Summary}

Hairs infected with Trichophyton discoides have been found on a scratching-post used by cattle infected with ringworm.

The parasitic spores of $T$. discoides in hair have been shown to survive for 15 months or longer when stored in the laboratory at room temperature.

$T$. discoides has been found to grow on sterilized soil and cow dung inoculated with infected hairs or with active cultures and incubated at $26^{\circ} \mathrm{C}$. On the cow dung and one of the soil samples a conidial form of the fungus developed.

It is tentatively concluded that under natural conditions infection may occur either by parasitic spores of the fungus that have survived in inanimate material or by conidia formed as the result of saprophytic growth in soil and animal droppings.

Acknowledgment is made to Dr. J. Martin Beare and Dr. I. Martin-Scott, through whom the farm specimens were obtained. REFERENCES

Ajello, L., and Zeidberg, L. D. (1951). Science, 113, 662

Blank, F.' (1953). Canad. J. comp. Med., 17, 277.

Emmons, C. W. (1949). Publ. Hith Rep. (Wash.), 64, 892

Georg, L. K. (1950). Ann. N.Y. Acad. Sci., 50, 1315 .

Gordon, M. A. (1953). J. invest. Derm., 20, 201.

- Ajello, L., Georg, L. K., and Zeidberg, L. D. (1952). Science, 116, 208.

Mackinnon, J. E., and Artagaveytia-Allende, R. C. (1948). J. Bact., 56, 91.

\section{Medical Memoranda}

\section{A Standard Cystoscope and Biopsy Forceps}

While no attempt should be made to curb individual ideas for the improvement of cystoscopic equipment it has long been evident that the standardization of as many parts as possible will make for economy, for simplicity of manufacture, and, more especially, for the ready interchange during use of one instrument for another. In the instruments here briefly described the systems of irrigation, of lighting, and of locking the various components in the sheath have been standardized.

\section{Cystoscope (FIG. 1)}

Irrigation is from a reservoir through a single large-bore three-way stopcock which gives a good inflow and outflow. A clean bladder can be inspected during and after gravity filling; a dirty one can be washed out through a faucet by a syringe whose nozzle fits it internally or by an evacuator which fits it externally. Once the telescope is in position further filling and emptying can be done without removing it.

The terminal for the lighting flex, which is sparkproof to comply with modern requirements, is always directly opposite the irrigating cock. Both are fixed to a rotating collar and can remain in position without the irrigating tubes and cord becoming entangled whilst the cystoscope is freely turned through 360 degrees in either direction.

The obturator, telescope, or faucet can be securely locked in position and easily unlocked by aligning two short vertical posts which indicate the upper side of the sheath and the component.

The set (Fig. 1) includes two sheaths, a circular one of size 42 Bé $(21 \mathrm{Ch})$ and an oval one of 48 Bé $(24 \mathrm{Ch})$. The same obturator, telescopes, irrigating stopcock, and faucets are used for each, and both have the same type of lamp of high efficiency with a festoon filament giving considerably more light than the usual cystoscopic bulb. The large-field examination telescope with an angle of view of 76 degrees in water covers a field of approximately $1 \frac{1}{2}$ in. $(3.8 \mathrm{~cm}$.) diameter at a distance of 1 in. $(2.5 \mathrm{~cm}$.). To obviate the need for a loose fin (which sometimes falls out) two more telescopes are provided-one with a double and one with a single catheterizing attachment. Each has an angle of view in water of 50 degrees and covers a field of approximately 1 in. $(2.5 \mathrm{~cm}$.) diameter at 1 in. $(2.5 \mathrm{~cm}$.) distance. The double catheterizing attachment admits two No. 12 Bé catheters through either sheath; the single attachment admits a No. 16 Bé electrode through the small sheath, or a No. 20 or operating scissors, etc., through
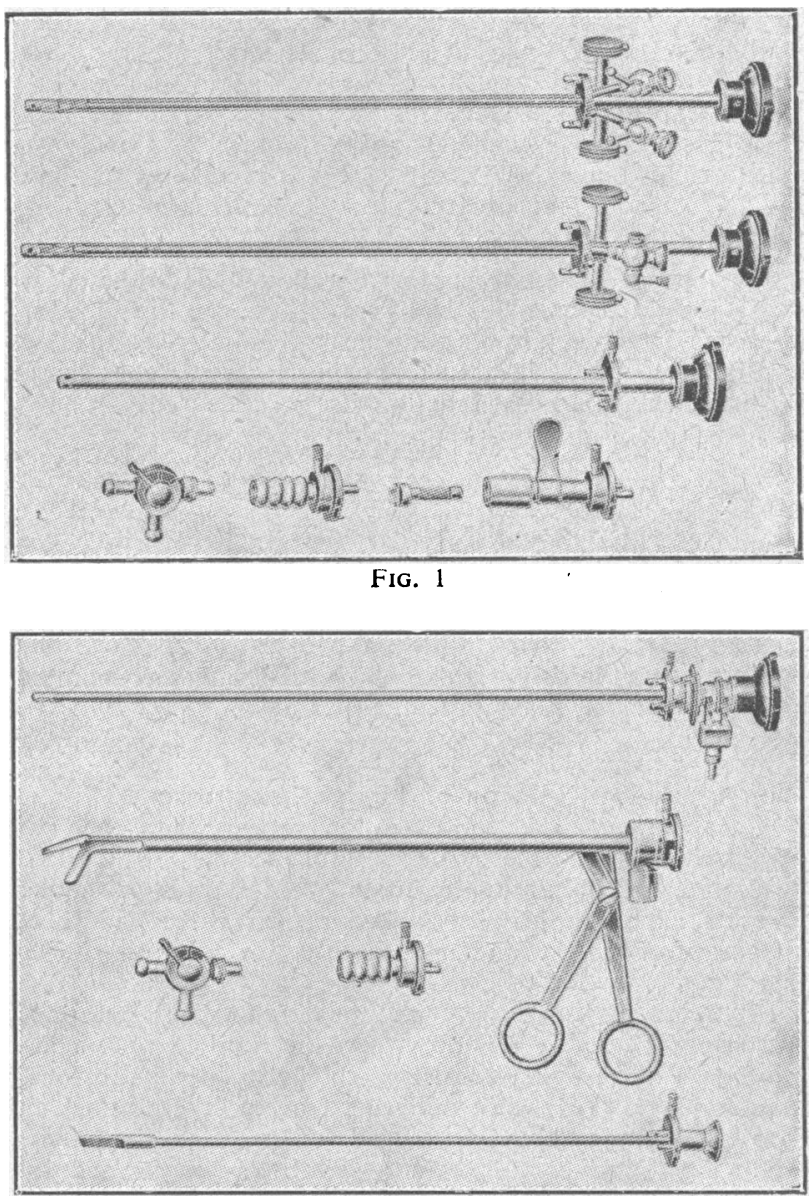

FIG. 2

the large sheath. The maximum working distance has been allowed between the eyepiece and the catheter spouts. The arrangement of the prism allows full inspection of the posterior urethra if the water inlet is kept open during examination.

The cystoscope is supplied in a perforated metal box, in which it can be boiled, or in a mahogany case.

For diagnostic cystoscopy a smaller version of the examination instrument has been made of size $36 \mathrm{Bé}(18 \mathrm{Ch})$; it is useful for out-patient work under local analgesia.

\section{Cystoscopic BIOPSY Forceps (FIG. 2)}

This makes use of the same irrigating stopcock and faucet as the cystoscope. The lamp terminal is connected to the telescope by a forked clip, and if the cystoscopic lead is used the current must first be lowered, as the lamp is smaller. The field of vision of the telescope has a fore-oblique inclination of about $\mathbf{7 0}$ degrees from the horizontal to give a better view of the jaws; the telescope can be rotated through 60 degrees to allow a growth to be inspected before the jaws are brought into position. 